\title{
Inflammatory agents partially explain changes in cortical thickness and surface area related to body mass index in adolescence
}

Prats-Soteras, X..$^{a, b, c}$; Jurado, M.A. ${ }^{a, b, c}$; Ottino-González, J., ${ }^{a, b, c}$; García-García, I.d ; Segura, B. ${ }^{b, e}$; Caldú, X. ${ }^{\mathrm{a}, \mathrm{b}, \mathrm{c}}$; Sánchez-Garre, C. ${ }^{\mathrm{f} h \mathrm{~h}}$; Miró, N. ${ }^{\mathrm{f} h}$; Tor, C. ${ }^{\mathrm{g}, \mathrm{h}}$; Sender-Palacios, M.g.h ; Garolera, M. ${ }^{\text {h,i }}$

${ }^{a}$ Departament de Psicologia Clínica i Psicobiologia, Universitat de Barcelona, Spain

$\mathrm{b}$ Institut de Neurociències, Universitat de Barcelona, Spain

c Institut de Recerca Sant Joan de Déu, Hospital Sant Joan de Déu, Spain

${ }^{\mathrm{d}}$ Montreal Neurological Institute, McGill University, Canada

e Departament de Medicina, Universitat de Barcelona, Barcelona, Spain

${ }^{f}$ Pediatric Endocrinology Unit, Hospital de Terrassa, Consorci Sanitari de Terrassa, Spain

g CAP Terrassa Nord, Consorci Sanitari de Terrassa, Barcelona, Spain

h Brain, Cognition and Behavior Clinical Research Group, Consorci Sanitari de Terrassa, Barcelona, Spain

' Unitat de Neuropsicologia, Hospital de Terrassa, Consorci Sanitari de Terrassa, Barcelona, Spain

\section{Corresponding author:}

majurado@ub.edu

Word count: 3.672

Declarations of interest: none 


\section{ABSTRACT}

Background/Objectives: Excessive body mass index (BMI) has been linked to a low-grade chronic inflammation state. Unhealthy BMI has also been related to neuroanatomical changes in adults. However, research in adolescents is relatively limited and has produced conflicting results. This study aims to address the relationship between BMI and adolescents' brain structure as well as to test the role that inflammatory adipose-related agents might have over this putative link.

Methods: We studied structural MRI and serum levels of interleukin-6, tumor necrosis factor alpha (TNF- $\alpha$ ), C-reactive protein and fibrinogen in 65 adolescents (aged 12-21 years). Relationships between BMI, cortical thickness and surface area were tested with a vertex-wise analysis. Subsequently, we used backward multiple linear regression models to explore the influence of inflammatory parameters in each brain-altered area.

Results: We found a negative association between cortical thickness and BMI in the left lateral occipital cortex (LOC), the left fusiform gyrus and the right precentral gyrus as well as a positive relationship between surface area and $\mathrm{BMI}$ in the left rostral middle frontal gyrus and the right superior frontal gyrus. In addition, we found that higher fibrinogen serum concentrations were related to thinning within the left $\operatorname{LOC}(\beta=-0.45, p<0.001)$ and the left fusiform gyrus $(\beta=-$ $0.33, p=0.035$ ), while higher serum levels of TNF- $\alpha$ were associated to a greater surface area in the right superior frontal gyrus $(\beta=0.32, p=0.045)$.

Conclusions: These results suggest that adolescents' body mass increases are related with brain abnormalities in areas that could play a relevant role in some aspects of feeding behavior. Likewise, we have evidenced that these cortical changes were partially driven by inflammatory agents such as fibrinogen and TNF- $\alpha$. 


\section{INTRODUCTION}

Overweight and obesity have become a pandemic. Child and-youth obesity is rising at an alarming rate. According to the World Health Organization (WHO), over 340 million children and adolescents aged 5-19 were overweight or obese in 2016 [1]. This is a worldwide source of concern because excessive weight during youth has been associated with an increased incidence of cardiometabolic diseases (e.g., type II diabetes, stroke, and hypertension), some types of cancer, and premature mortality in adulthood [2].

Excessive weight has been related to neuroanatomical changes in adults. Mainly, increases in body mass index (BMI) have been related to a wide-spread pattern of cortical gray matter volume (GMV) reductions $[3,4]$. In pediatric populations, although scarce, findings are in line with those described in adults, mostly in frontal and limbic regions [5-8].

Despite cortical GMV has often been used to measure gray matter density of the cortical mantle, it is worth noting that cortical GMV can be regarded as the product of thickness and surface area $[9,10]$. For this reason, analyzing cortical thickness and surface area separately could improve the specificity of the results, since a loss of GMV may reflect either reduced thickness, reduced area, or both [11]. While cortical thinning could provide some indication of neural loss, reduced size of neural cell bodies or degradation, surface area measures could mirror the tension or shrinkage of underlying white matter fibers [12]. In addition, these two constitutive components of cortical volume seem to be influenced by different genetic and cellular processes and follow distinct patterns of development [13]. Therefore, the study of cortical thickness and surface area separately can provide more accurate information about gray matter changes.

To date, studies in adolescents assessing the relationship between cortical thickness and body weight are scarce and have produced conflicting results. While two studies showed a negative link between obesity and cortical thickness [14, 15], others found no relationship with obesity or BMI [16-19]. Regarding the association between BMI and surface area, only one study has examined this which yielded null results [18].

Excessive weight is related to a low-grade chronic inflammation state [19-21] that might potentially lead to oxidative stress scenarios [22]. Both hypertrophied adipocytes and adipose tissue-resident macrophages produce inflammatory mediators such as interleukin-6 (IL-6), tumor necrosis factor alpha (TNF- $\alpha$ ), C-reactive protein (CRP) and fibrinogen [23-26]. Although a healthy brain is an immune-privileged organ due to the blood-brain barrier shielding properties [27], adipose-related inflammatory by-products can cross and disrupt its permeability, amplifying and sustaining a chronic inflammatory milieu $[22,28,29]$.

As abovementioned, research exploring neuroanatomical correlates of BMI in adolescents is relatively limited, particularly in terms of cortical thickness and surface area. Our study has two aims: 1) to address the relationship between BMI and adolescents' brain structure and 2) to test if this relationship could be explained by adipose-related levels of inflammatory biomarkers. We expect to find cortical changes related to an increase in BMI. Likewise, we assume that such connection will be partially explained by the presence of inflammatory agents. 


\section{MATERIALS AND METHODS}

\section{Participants}

This study includes 65 adolescents (age $=15.89 \pm 2.72$ years; 33 females), who were recruited from public primary care centers belonging to the Consorci Sanitari de Terrassa (Spain). All of them met two inclusion criteria: (1) being aged from 12 to 21 years old and (2) having a sex and age-specific BMI over the $5^{\text {th }}$ percentile according to the 2000 Centers for Disease Control and Prevention (CDC) growth charts [30]. Volunteers older than 17 had to show a BMI higher than $18.5 \mathrm{~kg} / \mathrm{m}^{2}$.

Individuals who met inclusion criteria and agreed to participate underwent a medical evaluation and a blood-sample, both performed in the Pediatric Endocrinology Unit at the Hospital de Terrassa in adolescents younger than 19 years old, and in the CAP Terrassa Nord for older participants. In this visit, participants' clinical history were reviewed and anthropometric measures (i.e., weight and height) were taken to exclude those who presented (1) history of psychiatric illness (including eating disorders such as bulimia), (2) history of regular drug use (3) developmental, (4) neurological, or (5) systemic disorders (e.g., hyper or hypothyroidism and diabetes). Additionally, (6) meeting metabolic syndrome criteria [31] also was an exclusion criteria for participants older than 17 years old. The presence of metabolic syndrome in adolescents under 18 years of age was not taken into account because there is no general consensus to define pediatric metabolic syndrome [32].

Participants who did not have any medical exclusion criteria went through a neuropsychological assessment to discard (7) the presence of global cognitive impairment (scalar score lower than 7 in vocabulary subtests of Wechsler batteries $[33,34]$ was interpreted as an estimated IQ below 85). Finally, adolescents who did not present any of the exclusion criteria abovementioned were proposed to undergo a magnetic resonance imaging (MRI). For this work, only those who accepted undertake this procedure were included in the study.

The final sample was composed by 65 adolescents. The flow of included and excluded participants is detailed in depth in Supplementary Material section (Appendix A.1). An overview of demographic, anthropometric and inflammatory characteristics is shown in Table 1.

This study was approved by the Institutional Ethics Committee of the University of Barcelona (CBUB); Institutional Review Board (IRB 00003099, assurance number: FWA00004225; http:// www.ub.edu/recerca/comissiobioetica.htm). The research was conducted in accordance with the Helsinki Declaration. Written informed consent was obtained from each participant (if older than 18 years old) or their parents prior to taking part in the study and after explaining the research purpose and procedures.

\section{Image acquisition}

Sixty-five adolescents underwent an MRI acquisition on a 3T MAGNETON Trio (Siemens, Germany) at the Institut d'Investigacions Biomeddiques August Pi I Sunyer (IDIBAPS) from the Centre de Diagnòstic per la Image Clínic (CDIC). We acquired a high resolution T1-weighted 3D using a Magnetization Prepared Rapid Acquisition Gradient echo (MPRAGE) sequence with the following parameters: repetition time $2300 \mathrm{~ms}$; echo time $2.98 \mathrm{~ms}$; inversion time $900 \mathrm{~ms}$. A total 
of 240 contiguous $1-\mathrm{mm}$ slices were acquired using a $256 \times 256$ matrix with an in-plane resolution of $1 \times 1 \mathrm{~mm}^{2}$.

\section{Data processing}

We performed the preprocessing and analysis of cortical thickness and surface area using standard procedures in FreeSurfer software (Version 6.0) (https://surfer.nmr.mgh.harvard.edu). Briefly, this process included motion correction and T1 averaging [35], removal of non-brain tissue [36], intensity normalization [37], cortical parcellation [38] and tessellation of gray/white matter tissue. Cortical thickness is represented by the distance between gray/white boundary and the gray/cerebrospinal fluid boundary at each vertex on the surface [39]. Once finished, each resulting image was visually inspected for inaccuracies in white matter and pial surfaces. Manual editing was performed when required.

\section{Inflammation biomarkers}

Blood samples were obtained from each participant in fasting state to obtain serum levels of pro-inflammatory biomarkers (TNF- $\alpha$, IL-6, high-sensitivity C-reactive protein (hs-CRP) and fibrinogen). This procedure was performed between 8:00 and 8:30 AM in the Pediatric Endocrinology Unit at the Hospital de Terrassa in participants younger than 19 and in the CAP Terrassa Nord for older volunteers. Blood samples were preserved at $-80^{\circ} \mathrm{C}$ at the Logistics Park of Health (CatLab) until analyzed. Serum concentrations of hs-CRP and fibrinogen were determined in CatLab through nephelometry (Beckman Coulter Immage 800) and PT-derived fibrinogen ( $F B_{P T}$ ) assay, respectively. Howbeit, fibrinogen levels of 29 adolescents were measured with STA-Neoplastin-Plus reactive (STA-Rack) while for the rest of participants was used Recombiplastin $2 \mathrm{G}$ reactive (ACLTOP 700). TNF- $\alpha$ and IL- 6 concentrations were determined at the Research Center on Metabolism (Universitat de Barcelona). TNF- $\alpha$ was measured using a Quantikine HS ELISA Human TNF- $\alpha$ (R\&D Systems, Ref. HSTAOOE Lot P174731) and IL-6 were determined by Quantikine HS ELISA Human IL-6 (R\&D Systems, Ref. HS600C Lot P178994). All these immunoassays were performed according to the manufacturer's instructions.

\section{BMI calculations}

$\mathrm{BMI}$, which results from dividing the weight in kilograms $(\mathrm{kg})$ by the square of height in meters $\left(\mathrm{m}^{2}\right)$, is the most common anthropometric measure used to determine obesity in adults [1]. Likewise, in pediatric population, the BMI is also used as a measure of adiposity since it is strongly correlated with body fat mass [40].

Healthy BMI range in childhood varies considerably with age. Hence, in order to achieve a comparable measurement of $\mathrm{BMI}$ among participants in our sample, we transformed $\mathrm{BMI}$ into BMI z-score (BMIz) using the $2000 \mathrm{CDC}$ growth charts [30]. These guidelines allow the obtention of age and sex-specific BMI percentiles and BMIz. Although both are equivalent, we decided to use BMIz because it is more suitable for statistical analysis [41]. Twenty-one-year-old participants had they BMIz calculated as if they were 20. 


\section{Statistical analyzes}

Brain structure was assessed using two measures: cortical thickness and surface area. First, we explored the relationship between BMI, cortical thickness and surface area in a vertex-by-vertex fashion through Query Design Estimate Contrast (Qdec) interface of FreeSurfer. Age, gender (discrete variable) and years of education were set as nuisance factors in all image analysis to avoid its potential biasing effects over brain structure. In addition, total surface area was also controlled in surface area analysis. Analyzes were performed separately for each hemisphere with a $10 \mathrm{~mm}$ full-width at half maximum kernel. Results were corrected for multiple comparisons using a Monte-Carlo null-Z simulation (10,000 repetitions). Statistical significance was set at a cluster-wise corrected $p$-value $(C W P)<0.05$. Significant clusters were reported according to the Desikan's atlas [38] in MNI305 space.

Second, we performed Spearman correlations between BMIz and the serum levels of each inflammatory agent obtained (i.e., IL-6, TNF- $\alpha$, CRP and fibrinogen) to ensure that said biomarkers were related with $\mathrm{BMI}$ in our sample.

Next, we addressed the putative link between inflammatory agents and the resulting neuroanatomical alterations originally linked to an increase in BMI. For this, cortical thickness and surface area values from significant clusters were extracted for further post-hoc analyzes in IBM SPSS Statistics (version 23). We used backward multiple linear regression models to explore the influence of all inflammatory parameters with each significant cluster. Here we used standardized residuals to control for the nuisance factors included in our previous vertex-wise analyzes. The significance threshold was set at Bonferroni-adjusted $p$-value $<0.05$. We also examined critical parameters of regression analysis to assure assumption fulfillment [42], which are available in the Supplementary Material section (Appendix A.2).

Table 1

Demographic, anthropometric and inflammatory characteristics.

\begin{tabular}{|c|c|c|c|}
\hline & Mean & SD & Range \\
\hline Age (years) & 15.89 & 2.72 & $12-21$ \\
\hline BMIz & 1.07 & 1.06 & $-1.28-2.69$ \\
\hline Gender (F/M) & \multicolumn{2}{|c|}{$33 / 32$} & \\
\hline Years education & 9.74 & 2.38 & $6-16$ \\
\hline IQ estimation (scalar score) & 11.17 & 2.22 & $7-17$ \\
\hline hs-CRP (mg/dL) & 3.45 & 9.11 & $0.12-67.80$ \\
\hline TNF- $\alpha(p g / m L)$ & 0.89 & 0.35 & $0.26-1.95$ \\
\hline IL-6 (pg/mL) & 2.41 & 3.11 & $0.38-18.76$ \\
\hline Fibrinogen $(\mathrm{g} / \mathrm{L})$ & 3.67 & 0.81 & $2.23-6.04$ \\
\hline
\end{tabular}

$B M I z=$ body mass index $z$-score $; F=$ female; $M=$ male; $I Q$ estimation = Intelligence Quotient estimation; $h s-C R P=$ high-sensitivity $C$-reactive protein; $m g / d L=$ milligrams per deciliter; $T N F-\alpha$ = tumor necrosis factor alpha; $\mathrm{pg} / \mathrm{mL}=$ picograms per milliliter; $\mathrm{L}-6=$ = Interleukin $-6 ; \mathrm{g} / \mathrm{L}=$ grams per liter. 


\section{RESULTS}

\section{Vertex-wise analyzes}

There was a negative relationship between cortical thickness $(\mathrm{mm})$ and BMIz in the left lateral occipital cortex (LOC), the left fusiform gyrus and the right precentral gyrus. Regarding surface area $\left(\mathrm{mm}^{2}\right)$, we found a positive relationship with BMlz in the left rostral middle frontal gyrus and the right superior frontal gyrus (Table 2; Figure 1-2).

Table 2.

Vertex-wise results.

\begin{tabular}{lccccccc}
\hline Peak location & $\begin{array}{c}\text { Cluster size } \\
\left(\mathrm{mm}^{2}\right)\end{array}$ & \multicolumn{2}{c}{ Peak MNI coordinates } & $\begin{array}{c}\text { Statistical } \\
\text { Thickness }\end{array}$ & & & $\begin{array}{c}\text { Corrected } \\
\text { p-value }\end{array}$ \\
\hline L-LOC & 958.80 & -41.6 & -78.8 & -2.5 & -2.756 & 0.0092 \\
L-Fusiform & 885.96 & -32.9 & -38.3 & -17.8 & -3.166 & 0.0177 \\
R-Precentral & 1748.90 & 22.7 & -19.0 & 55.2 & -3.507 & 0.0001 \\
Surface area & & & & & & \\
L-Rostral middle frontal & 2528.97 & -34.9 & 29.5 & 31.7 & 3.29 & 0.0014 \\
R-Superior frontal & 2930.23 & 7.3 & 31.8 & 44.1 & 2.646 & 0.0008 \\
\hline
\end{tabular}

$L=$ left $R=$ right LOC = lateral occipital cortex.

\section{LH Cortical thickness}
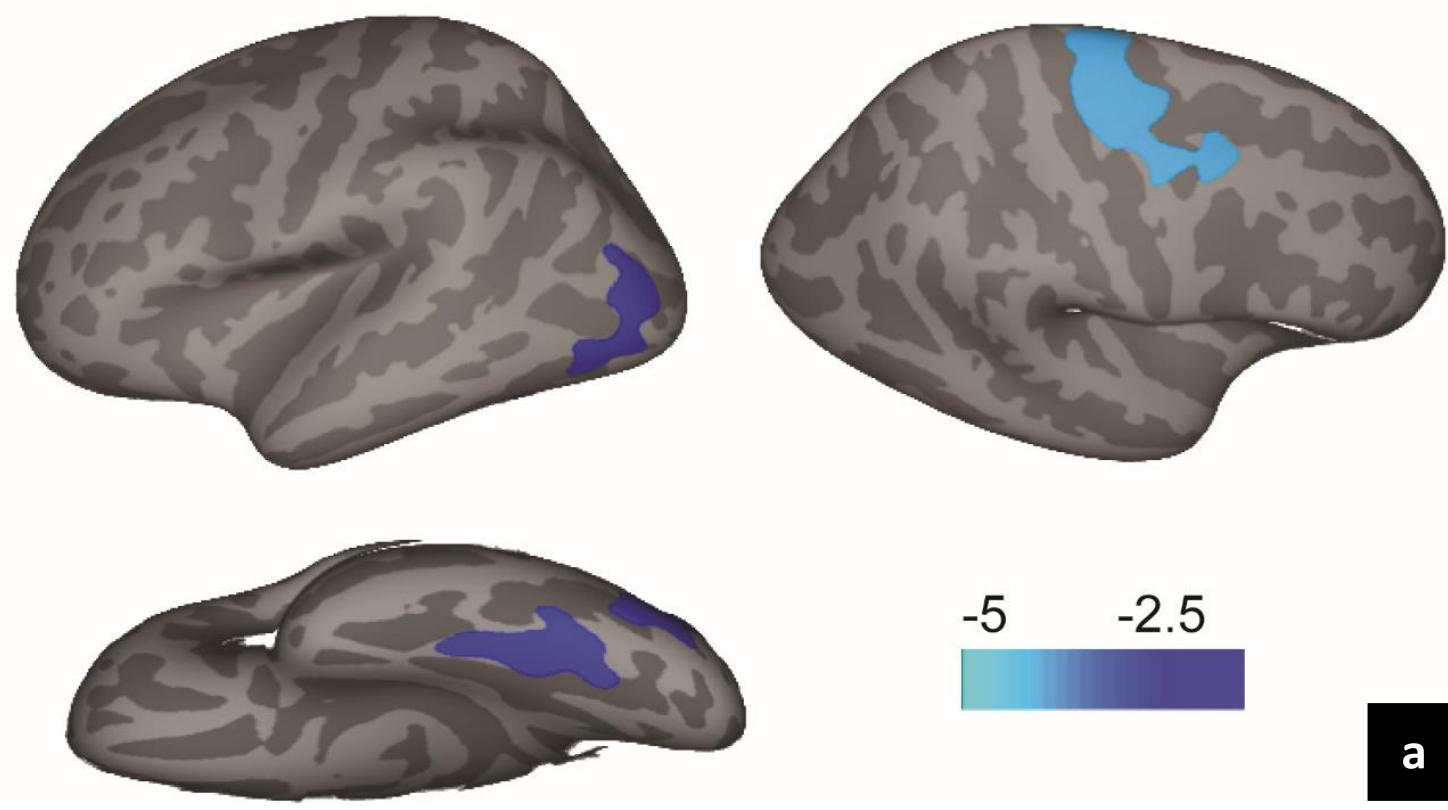


\section{LH Surface area}
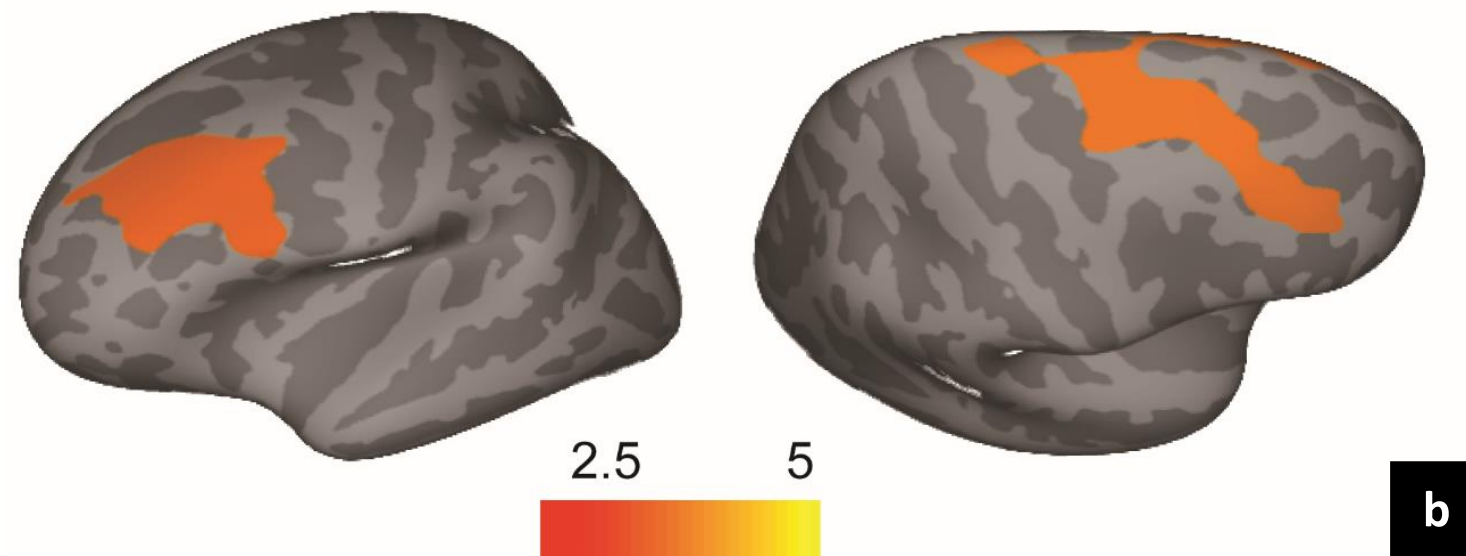

Figure 1. Lateral and inferior views of the thickness reduction in relation to BMIz after adjusting for age, gender and years of education. Significant clusters in the left LOC, the left fusiform gyrus and the right precentral gyrus (a). Lateral and superior views of increasing surface area in relation to the BMIz after adjusting for age, gender, years of education and total surface area. Significant clusters in the left rostral middle frontal gyrus and the right superior frontal gyrus (b). Scatter plots are shown in Figure 2.
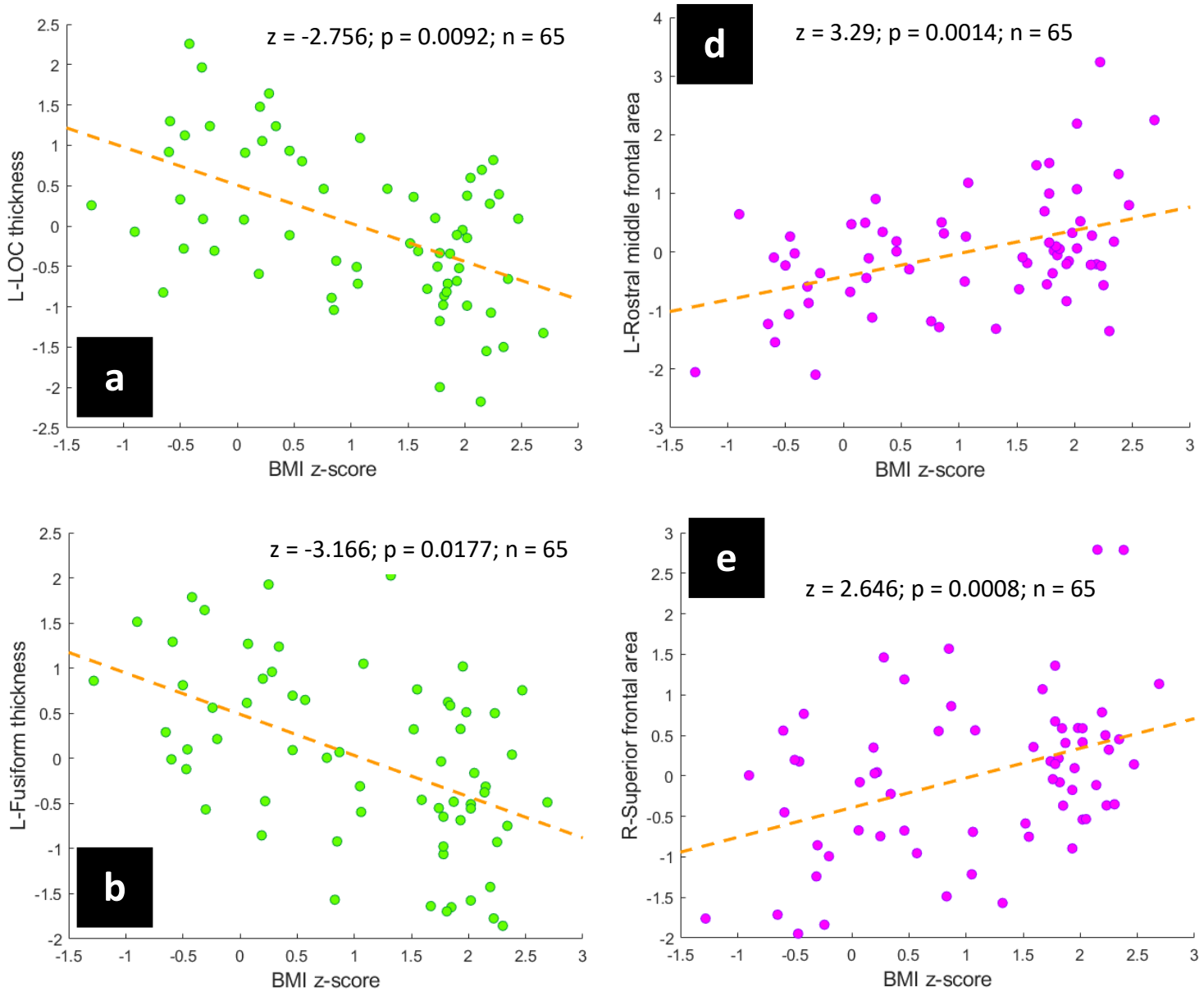


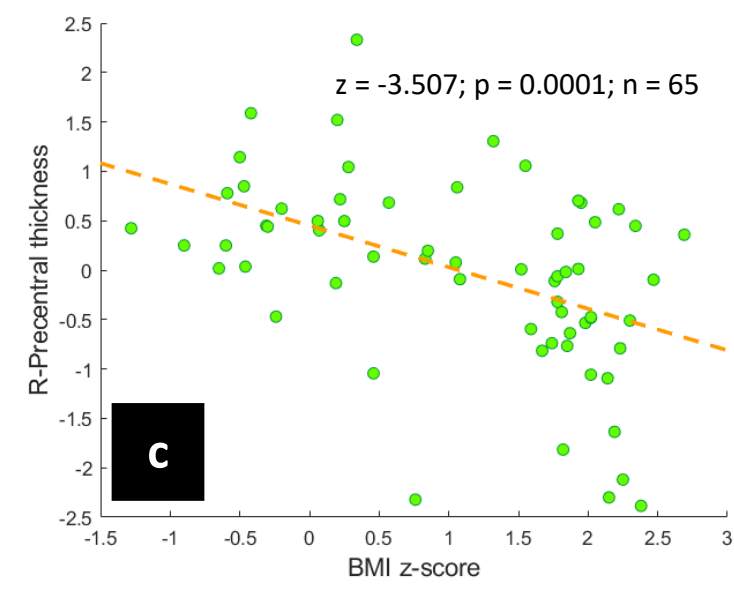

Figure 2. Scatter plots showing association between BMIz and standardized residuals of cortical thickness in the left LOC (a) the left fusiform (b) and the right precentral (c) gyri; BMIz and standardized residuals of surface area in the left rostral middle frontal (d) and the right superior frontal (e) gyri.

\section{Correlation analyzes between BMIz and inflammatory biomarkers}

Spearman correlations reveled that BMIz was positively related with serum levels of hs-CRP $\left(r_{s}=\right.$ $0.568, p<0.001)$, IL-6 $\left(r_{s}=0.559, p<0.001\right)$, TNF- $\alpha\left(r_{s}=0.320, p=0.009\right)$ and fibrinogen $\left(r_{s}=0.514\right.$, $p<0.001)$. All of them survived Bonferroni adjustment. See Supplementary Material section (Appendix A.3).

\section{Post-hoc regression models of inflammation biomarkers}

Post-hoc regression analyzes showed that cortical thickness reductions associated with higher BMIz were partially explained by the increase in serum levels of fibrinogen in the left $L O C\left(R^{2}=\right.$ $0.19, \beta=-0.45, p<0.001)$ and the left fusiform gyrus $\left(R^{2}=0.09, \beta=-0.33, p=0.035\right)$. Contrarily, the right precentral gyrus thickness did not exhibit a significant relationship with fibrinogen values $(\beta=-0.24, p=0.057$ ). Likewise, the surface increases within the right superior frontal gyrus were explained to some degree through serum levels of TNF- $\alpha\left(R^{2}=0.09, \beta=0.32, p=\right.$ 0.045). In addition, although blood hs-CRP concentrations also partly explained surface increases in the left rostral middle frontal gyrus $\left(R^{2}=0.06, \beta=0.28, p=0.024\right)$, it did not pass the Bonferroni adjustment $(\beta=0.28, p=0.12)$. Backward regression models are presented in detail in Supplementary Material section (Appendix A.4). Best-fitting significant uncorrected regression models with adjusted $p$-value are shown in Table 3. Figure 3 shows the models that survived the multiple comparisons correction. 
Table 3.

Best-fitting significant uncorrected regression models with adjusted $p$-value.

\begin{tabular}{lccccccc}
\hline & Biomarker & ${ }^{+} \mathrm{R}^{2}$ & $\beta$ & $\mathrm{t}$ & $\mathrm{SE}$ & $\mathrm{p}$ & $\begin{array}{c}\text { Bonferroni } \\
\text { adjusted } \\
\mathrm{p} \text {-value }\end{array}$ \\
\hline $\begin{array}{l}\text { Thickness } \\
\text { L-LOC }\end{array}$ & Fibrinogen & 0.19 & -0.45 & -3.99 & 0.14 & $<0.001^{* * *}$ & $<0.001^{* * *}$ \\
L-Fusiform & Fibrinogen & 0.09 & -0.33 & -2.77 & 0.14 & $0.007^{* *}$ & $0.035^{*}$ \\
Surface area & & & & & & & \\
L-Ros mid frontal & hs-CRP & 0.06 & 0.28 & 2.31 & 0.01 & $0.024^{*}$ & 0.12 \\
R-Superior frontal & TNF- $\alpha$ & 0.09 & 0.32 & 2.70 & 0.33 & $0.009^{* *}$ & $0.045^{*}$ \\
\hline
\end{tabular}

${ }^{+}$Adjusted $R$ squared value; $S E=$ standard error; $L=$ left; $R=$ right; $L O C=$ lateral occipital cortex; Ros $=$ rostral; mid = middle; TNF- $\alpha=$ tumor necrosis factor alpha; $h s-C R P=$ high-sensitivity $C$ reactive protein; * $p<0.05$; $^{* *} p<0.01 ;{ }^{* * *} p<0.001$.

L-Fusiform: $\beta=-0.33 ; p=0.035$

L-Lateral occipital: $\beta=-0.45 ; p<0.001$

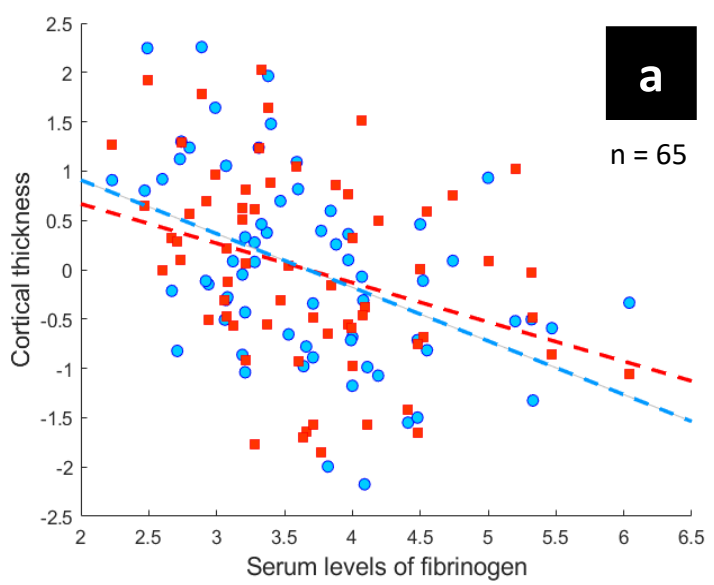

$\beta=0.32 ; p=0.045 ; n=65$

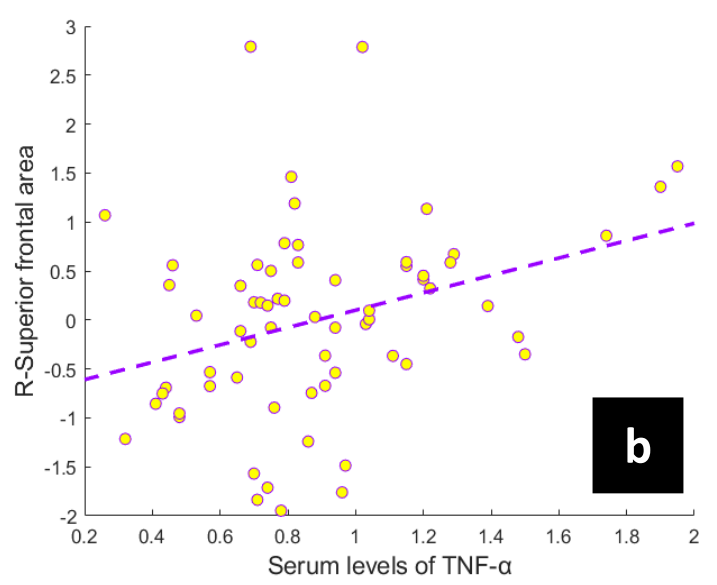

Figure 3. Scatter plots showing the association between standardized residuals of cortical thickness and blood fibrinogen concentration (a) and the link between standardized residuals of surface area and serum levels of TNF- $\alpha$ (b).

\section{DISCUSSION}

This study aimed to assess the correlation between BMI and neuroanatomical changes in adolescents as well as the role that inflammatory agents might have over this relationship. None of the teenagers included in the study had any obesity-related comorbidity. This rigorous selection of participants was carried out with the aim of trying to isolate as best as possible the effect of BMI on brain structure, avoiding the potential confounding effects from other clinical comorbidities associated with unhealthy excess weight (e.g., insulin resistance, type 2 diabetes) 
bioRxiv preprint doi: https://doi.org/10.1101/698696; this version posted July 29, 2019. The copyright holder for this preprint (which was

\section{Associations between cortical gray matter and BMI}

Using a vertex-wise approach, we found cortical thickness reductions associated with an increase in the BMIz in the left LOC, extending to the inferior parietal cortex, the left fusiform gyrus and the right precentral gyrus, including the caudal middle frontal gyrus. Our results are highly consistent with studies conducted in adults. Cortical thinning linked to BMI was also described in the left LOC [43], as well as in the left inferior parietal cortex, including LOC and fusiform areas, and the right precentral gyrus [44]. Both studies carried out vertex-wise correlations with a wide range of BMI that included healthy and unhealthy values that are compatible with obesity.

However, our results are not in line with other work exploring cortical thickness changes related to $\mathrm{BMI}$ in teenagers. To date, two studies did not find an association between BMI and cortical thickness $[17,18]$. The discrepancy between our results and these works could be explained by the age range of the sample, especially the upper age limit, because while both studies included adolescents not older than 18 , we included participants in late adolescence, which comprises a stage between 18 and 21 years [45]. Moreover, this inconsistency also might account either because differences in the sample size or the software employed.

Even though cortical areas in which we identified thickness changes related to weight increase have not been detected in adolescents so far, there is evidence to think that these brain regions could be altered in teenagers at an unhealthy weight situation, as they are involved in some aspects of feeding behavior. Both the LOC and the fusiform gyrus are two of the most reported areas in $\mathrm{fMRI}$ studies that investigate neural response to food stimuli [46]. Additionally, left LOC has been pointed as an important area to extract the energy value of food [47]. On the other hand, although precentral gyrus abnormalities are not too contrasted in unhealthy weight gain, this area has been described as a component of motor sensory networks implicated in visual recognition and control for food tasks [48].

Regarding surface area, we found a positive correlation with BMIz in two clusters with maximum peaks in the left rostral middle frontal gyrus, extending to the pars opercularis and the caudal middle frontal gyrus, and the right superior frontal gyrus, which included the caudal middle frontal, the rostral middle frontal and the precentral gyri. Both areas belong to the dorsolateral prefrontal cortex (DLPFC). As far as we know, only Saute and colleagues [18] examined the possible association between adolescents' surface area and BMI. They did not find a relationship between surface area and BMI in 44 teenagers from 15 to 18 .

The DLPFC is among the latest brain regions to mature [49]. In typical development, the cortical area of the DLPFC shows age-related declines from 9 to 20 years old [50]. Accordingly, an increase in DLPFC surface area could be interpreted as an interference of the BMI-related inflammation with the prefrontal cortex synaptic pruning process. This mechanism could potentially reduce the effectiveness of frontal lobe functions in adolescence and later life. This speculation may be in line with the strong evidence that supports the existence of a negative relationship between executive functioning and unhealthy weight in teenagers [51, 52]. Nevertheless, smaller surface area in prefrontal regions has been associated with problems in executive functioning in adults [13]. Hence, more studies are needed to validate these results.

Another plausible explanation would be to consider that unhealthy BMI-increase may also be affecting underlying white matter, since tension-changes along the axons of white matter has 
bioRxiv preprint doi: https://doi.org/10.1101/698696; this version posted July 29, 2019. The copyright holder for this preprint (which was

been described as the primary driving force for cortical folding [53]. Therefore, changes in DLPFC area could also be an indirect consequence of possible white matter alterations.

\section{Cortical gray matter findings and proinflammatory agents}

Addressing another main objective, we found that the relationship between gray matter structure and BMI was partly explained by inflammatory agents. Higher fibrinogen serum concentrations were related to thinning within the left LOC and the left fusiform gyrus. Alternatively, higher serum levels of TNF- $\alpha$ were associated to a greater surface area in the right superior frontal gyrus.

Although the relationship between obesity and chronic inflammation is well known, our results suggest that inflammatory-related agents are able to disrupt brain structure. The reason why fibrinogen and TNF- $\alpha$ are related to opposite patterns (i.e., decrease and increase) and different metrics (i.e., thickness and surface) remains unclear. Two possible explanations could be that (1) the course of the neuroinflammatory response may be disharmonious among different brain regions, and (2) the effect of neuroinflammation could be subjected to the specific developmental stage of each cortical region.

Diet-induced obesity could alter the permeability of the blood-brain barrier [19], whose permeability is no longer uniform under physiological conditions [54]. Specifically, it appears that the blood-brain barrier of the cerebellum may be more permeable than in other brain regions [55]. Thus, cortical regions near the cerebellum might also be more permeable, which would make them more vulnerable to the harmful effects of neuroinflammation. Reduction in cortical thickness has been interpreted as a proxy of atrophy [56], as it might mirror neuronal loss, reduced size of neural cell bodies or degradation [12]. The brain regions we have described as thinner in relation to the BMI increase were those exhibiting a link with fibrinogen. Typically, under healthy conditions, and unlike cytokines, this inflammatory agent should not be present in the central nervous system [57]. Thus, this finding could be in line with the hypothesis that the increase in BMI is associated to disruptions of the blood-brain barrier and could point towards the fact that the inflammatory response might be at a more advanced stage. Other studies have demonstrated that fibrinogen is related with both neural death and synaptic degradation [58] as well as with reductions in neural density [59]; findings that could fit with a reduction in cortical thickness. Based on this argument, the fact that the changes related to $\mathrm{BMI}$ in the area of DLPFC were related to TNF- $\alpha$ but not to fibrinogen could be due to the heterogeneous permeability of blood-brain barrier among different brain regions. At this moment, the integrity of the blood-brain barrier of this region would not be so compromised as to allow fibrinogen access. Thus, the neuroinflammatory response within DLPFC might be an earlier stage, still incapable of causing a decrease in gray matter. However, after some time, the course of this response would continue advancing and would be able to decrease gray matter. This idea would be congruent with results of Cazettes and colleagues [60], since they found that the lateral orbitofrontal cortex volumes of overweight/obese adults were negatively associated with fibrinogen.

As above mentioned, all regions of the brain do not end their development at the same time, being the prefrontal cortex the last brain region to reach adult maturity [49]. Hence, it might be possible that potential neuroinflammation response related to BMI could exercise different effects in different cortical regions as well as make different brain regions more susceptible to 
certain inflammatory biomarkers depending on the specific moment of development they are going through. Finally, it is worth considering that both possible interpretations (i.e., the desynchronized course of the neuroinflammatory response and the specific developmental stage of each brain region) might be complementary rather than exclusive.

\section{LIMITATIONS AND FUTURE DIRECTIONS}

This study has some limitations that should be acknowledged. The size of our sample limits the robustness of our results. In addition, we also have methodological limitations that it is worth to be pointed. The 2000 CDC growth charts [30] only allow to calculate BMIz for individuals up to 20 years. Our study, however, included participants up to 21 years of age in order to cover until the end of the central nervous system development. Finally, the cross-sectional design of this study unfortunately does not allow us concluding upon causality. Therefore, as it is premature to draw firm conclusions, we encourage other researchers to continue the study of the possible relationship between cortical changes associated to $\mathrm{BMI}$ and inflammatory agents in larger samples. The confirmation of this association could help the development of targeted interventions aimed at reducing peripheral obesity-related inflammation in order to reduce the impact of neuroinflammatory state and its harmful effects on the brain.

\section{CONCLUSIONS}

We have found a relationship between BMI and brain structure in adolescents. Specifically, we have detected that body mass increases were associated with thinner cortices in the left LOC, the left fusiform and the right precentral gyrus as well as with greater surface area in the left rostral middle frontal gyrus and the right superior frontal gyrus. All these areas could play a relevant role in some aspects of feeding behavior. Moreover, we have evidenced that these cortical changes were partially driven by inflammatory agents such as fibrinogen and TNF- $\alpha$.

\section{ACKNOWLEDGMENTS}

The authors thank all participants in the study without whose support the work would not have been possible.

\section{Funding}

This work was supported by grants from MINECO to Dr. María Ángeles Jurado (PSI2017-86536C2-1-R) and Dr. Maite Garolera (PSI2017-86536-C2-2-R) and from the Generalitat de Catalunya to Xavier Prats-Soteras (FI-DGR 2017).

\section{Author contributions}

XPS, MAJ, JOG, IGG, BS, XC, and MG contributed to study design and conception, analyses and results interpretation. XPS, JOG, IGG, CSG, NM, CT and MSP participated in data acquisition. 
Additionally, all authors critically revisited the work, approved its final version for publishing, and agreed to be accountable for all aspects of such work.

\section{CONFLICT OF INTEREST}

The authors declare that they have no conflict of interest. 


\section{REFERENCES}

1. WHO. (2018). Obesity and overweight. Retrieved January 23, 2019, from https://www.who.int/news-room/fact-sheets/detail/obesity-and-overweight

2. Reilly, J. J., \& Kelly, J. (2011). Long-term impact of overweight and obesity in childhood and adolescence on morbidity and premature mortality in adulthood: systematic review. International Journal of Obesity, 35(7), 891-898. https://doi.org/10.1038/ijo.2010.222

3. García-García, Isabel, Michaud, A., Dadar, M., Zeighami, Y., Neseliler, S., Collins, D. L., ... Dagher, A. (2018). Neuroanatomical differences in obesity: meta-analytic findings and their validation in an independent dataset. International Journal of Obesity, 9. https://doi.org/10.1038/s41366-018-0164-4

4. Herrmann, M. J., Tesar, A., Beier, J., Berg, M., \& Warrings, B. (2018). Grey matter alterations in obesity: A meta-analysis of whole-brain studies. Obesity Reviews, obr.12799. https://doi.org/10.1111/obr.12799

5. Alosco, M. L., Stanek, K. M., Galioto, R., Korgaonkar, M. S., Grieve, S. M., Brickman, A. M., ... Gunstad, J. (2014). Body mass index and brain structure in healthy children and adolescents. International Journal of Neuroscience, 124(1), 49-55. https://doi.org/10.3109/00207454.2013.817408

6. Kennedy, J. T., Collins, P. F., \& Luciana, M. (2016). Higher adolescent body mass index is associated with lower regional gray and white matter volumes and lower levels of positive emotionality. Frontiers in Neuroscience, 10(SEP), 1-12. https://doi.org/10.3389/fnins.2016.00413

7. Maayan, L., Hoogendoorn, C., Sweat, V., \& Convit, A. (2011). Disinhibited eating in obese adolescents is associated with orbitofrontal volume reductions and executive dysfunction. Obesity (Silver Spring, Md.), 19(7), 1382-1387. https://doi.org/10.1038/oby.2011.15; 10.1038/oby.2011.15

8. Ou, X., Andres, A., Pivik, R. T., Cleves, M. a., \& Badger, T. M. (2015). Brain gray and white matter differences in healthy normal weight and obese children. Journal of Magnetic Resonance Imaging, 42(5), 1205-1213. https://doi.org/10.1002/jmri.24912

9. Vijayakumar, N., Allen, N. B., Youssef, G., Dennison, M., Yücel, M., Simmons, J. G., \& Whittle, S. (2016). Brain development during adolescence: A mixed-longitudinal investigation of cortical thickness, surface area, and volume. Human Brain Mapping, 37(6), 2027-2038. https://doi.org/10.1002/hbm.23154

10. Winkler, A. M., Greve, D. N., Bjuland, K. J., Nichols, T. E., Sabuncu, M. R., Håberg, A. K., ... Rimol, L. M. (2018). Joint Analysis of Cortical Area and Thickness as a Replacement for the Analysis of the Volume of the Cerebral Cortex. Cerebral Cortex, 28(2), 738-749. https://doi.org/10.1093/cercor/bhx308

11. Rimol, L. M., Nesvåg, R., Hagler, D. J., Bergmann, $\varnothing$., Fennema-Notestine, C., Hartberg, C. B., ... Dale, A. M. (2012). Cortical Volume, Surface Area, and Thickness in Schizophrenia and Bipolar Disorder. https://doi.org/10.1016/j.biopsych.2011.11.026

12. Worker, A., Blain, C., Jarosz, J., Chaudhuri, K. R., Barker, G. J., Williams, S. C. R., ... Simmons, A. (2014). Cortical thickness, surface area and volume measures in Parkinson's disease, multiple system atrophy and progressive supranuclear palsy. PloS One, 9(12), e114167. https://doi.org/10.1371/journal.pone.0114167

13. Tamnes, C. K., Zeller, B., Amlien, I. K., Kanellopoulos, A., Andersson, S., Due-Tønnessen, P., ... Fjell, A. M. (2015). Cortical surface area and thickness in adult survivors of pediatric acute lymphoblastic leukemia. Pediatric Blood \& Cancer, 62(6), 1027-1034. https://doi.org/10.1002/pbc.25386

14. Ross, N., Yau, P. L., \& Convit, A. (2015). Obesity, fitness, and brain integrity in 
adolescence. Appetite. https://doi.org/10.1016/j.appet.2015.03.033

15. Yau, P. L., Kang, E. H., Javier, D. C., \& Convit, A. (2014). Preliminary evidence of cognitive and brain abnormalities in uncomplicated adolescent obesity. Obesity, OO(00), n/a-n/a. https://doi.org/10.1002/oby.20801

16. de Groot, C. J., van den Akker, E. L. T., Rings, E. H. H. M., Delemarre-van de Waal, H. A., \& van der Grond, J. (2017). Brain structure, executive function and appetitive traits in adolescent obesity. Pediatric Obesity, 12(4), e33-e36. https://doi.org/10.1111/ijpo.12149

17. Sharkey, R. J., Karama, S., \& Dagher, A. (2015). Overweight is not associated with cortical thickness alterations in children. Frontiers in Neuroscience, 9(February), 1-7. https://doi.org/10.3389/fnins.2015.00024

18. Saute, R. L., Soder, R. B., Alves Filho, J. O., Baldisserotto, M., \& Franco, A. R. (2018). Increased brain cortical thickness associated with visceral fat in adolescents. Pediatric Obesity, 13(1), 74-77. https://doi.org/10.1111/ijpo.12190

19. Guillemot-Legris, O., \& Muccioli, G. G. (2017). Obesity-Induced Neuroinflammation: Beyond the Hypothalamus. Trends in Neurosciences, 40(4), 237-253. https://doi.org/10.1016/j.tins.2017.02.005

20. Reilly, S. M., \& Saltiel, A. R. (2017). Adapting to obesity with adipose tissue inflammation. Nature Reviews Endocrinology, 13(11), 633-643. https://doi.org/10.1038/nrendo.2017.90

21. Spyridaki, E. C., Avgoustinaki, P. D., \& Margioris, A. N. (2016). Obesity, inflammation and cognition. Current Opinion in Behavioral Sciences, 9, 169-175. https://doi.org/10.1016/j.cobeha.2016.05.004

22. Kim, Y. K., \& Won, E. (2017). The influence of stress on neuroinflammation and alterations in brain structure and function in major depressive disorder. Behavioural Brain Research, 329(April), 6-11. https://doi.org/10.1016/j.bbr.2017.04.020

23. Kang, M., Vaughan, R. A., \& Paton, C. M. (2015). FDP-E induces adipocyte inflammation and suppresses insulin-stimulated glucose disposal: effect of inflammation and obesity on fibrinogen B $\beta$ mRNA. American Journal of Physiology-Cell Physiology, 309(11), C767-C774. https://doi.org/10.1152/ajpcell.00101.2015

24. Miller, A. L., Lee, H. J., \& Lumeng, J. C. (2015). Obesity-associated biomarkers and executive function in children. Pediatric Research, 77(1-2), 143-147. https://doi.org/10.1038/pr.2014.158

25. Nguyen, J. C. D., Killcross, A. S., \& Jenkins, T. A. (2014). Obesity and cognitive decline: role of inflammation and vascular changes. Frontiers in Neuroscience, 8(OCT), 1-9. https://doi.org/10.3389/fnins.2014.00375

26. Vachharajani, V., \& Granger, D. N. (2009). Adipose tissue: A motor for the inflammation associated with obesity. IUBMB Life, 61(4), 424-430. https://doi.org/10.1002/iub.169

27. Chow, B. W., \& Gu, C. (2015). The Molecular Constituents of the Blood-Brain Barrier. Trends in Neurosciences, 38(10), 598-608. https://doi.org/10.1016/j.tins.2015.08.003

28. Miller, A. H., Haroon, E., Raison, C. L., \& Felger, J. C. (2013). Cytokine targets in the brain: Impact on neurotransmitters and neurocircuits. Depression and Anxiety, 30(4), 297-306. https://doi.org/10.1002/da.22084

29. Ryu, Jae K., \& McLarnon, J. G. (2009). A leaky blood-brain barrier, fibrinogen infiltration and microglial reactivity in inflamed Alzheimer's disease brain. Journal of Cellular and Molecular Medicine, 13(9 A), 2911-2925. https://doi.org/10.1111/j.15824934.2008.00434.x

30. Kuczmarski, R. J., Ogden, C. L., Guo, S. S., Grummer-Strawn, L. M., Flegal, K. M., Mei, Z., ... Johnson, C. L. (2002). 2000 CDC Growth Charts for the United States: methods and development. Vital and Health Statistics. Series 11, Data from the National Health Survey, (246), 1-190. Retrieved from http://www.ncbi.nlm.nih.gov/pubmed/12043359 
31. Alberti, K. G. M. M., Eckel, R. H., Grundy, S. M., Zimmet, P. Z., Cleeman, J. I., Donato, K. A., ... Smith, S. C. (2009). Harmonizing the Metabolic Syndrome. Circulation, 120(16), 1640-1645. https://doi.org/10.1161/CIRCULATIONAHA.109.192644

32. Yau, P. L., Castro, M. G., Tagani, A., Tsui, W. H., \& Convit, A. (2012). Obesity and metabolic syndrome and functional and structural brain impairments in adolescence. Pediatrics, 130, e856-64. https://doi.org/10.1542/peds.2012-0324

33. Wechsler, D. (2007). WISC-IV: Escala de Inteligencia de Wechsler para Niños-IV (2a ed.). Madrid: TEA.

34. Wechsler, D. (1999). WAIS III. Escala de Inteligencia de Wechsler para Adultos III (Adaptación espa-ola ed.). Madrid: TEA Editores, S.A.

35. Reuter, M., Rosas, H. D., \& Fischl, B. (2010). Highly accurate inverse consistent registration: A robust approach. Neurolmage, 53(4), 1181-1196. https://doi.org/10.1016/j.neuroimage.2010.07.020

36. Ségonne, F., Dale, A. M., Busa, E., Glessner, M., Salat, D., Hahn, H. K., \& Fischl, B. (2004). A hybrid approach to the skull stripping problem in MRI. Neurolmage, 22(3), 1060-1075. https://doi.org/10.1016/j.neuroimage.2004.03.032

37. Sled, J. G., Zijdenbos, A. P., \& Evans, A. C. (1998). A nonparametric method for automatic correction of intensity nonuniformity in MRI data. IEEE Transactions on Medical Imaging, 17(1), 87-97. https://doi.org/10.1109/42.668698

38. Desikan, R. S., Ségonne, F., Fischl, B., Quinn, B. T., Dickerson, B. C., Blacker, D., ... Killiany, R. J. (2006). An automated labeling system for subdividing the human cerebral cortex on MRI scans into gyral based regions of interest. Neurolmage, 31(3), 968-980. https://doi.org/10.1016/j.neuroimage.2006.01.021

39. Fischl, B., \& Dale, A. M. (2000). Measuring the thickness of the human cerebral cortex from magnetic resonance images. Proceedings of the National Academy of Sciences, 97(20), 11050-11055. https://doi.org/10.1073/pnas.200033797

40. Martin-Calvo, N., Moreno-Galarraga, L., \& Angel Martinez-Gonzalez, M. (2016). Association between Body Mass Index, Waist-to-Height Ratio and Adiposity in Children: A Systematic Review and Meta-Analysis. https://doi.org/10.3390/nu8080512

41. Must, A., \& Anderson, S. E. (2006). PEDIATRIC MINI REVIEW Body mass index in children and adolescents: considerations for population-based applications. International Journal of Obesity, 30, 590-594. https://doi.org/10.1038/sj.ijo.0803300

42. Field, A. P. (2005). Discovering statistics using SPSS :(and sex, drugs and rock' $n^{\prime}$ roll) (Vol. 2). London etc.: Sage Publications.

43. Medic, N., Ziauddeen, H., Ersche, K. D., Farooqi, I. S., Bullmore, E. T., Nathan, P. J., ... Fletcher, P. C. (2016). Increased body mass index is associated with specific regional alterations in brain structure. International Journal of Obesity, 40(7), 1177-1182. https://doi.org/10.1038/ijo.2016.42

44. Veit, R., Kullmann, S., Heni, M., Machann, J., Häring, H.-U., Fritsche, A., \& Preissl, H. (2014). Reduced cortical thickness associated with visceral fat and BMI. Neurolmage: Clinical, 6, 307-311. https://doi.org/10.1016/j.nicl.2014.09.013

45. Hardin, A. P., \& Hackell, J. M. (2017). Age Limit of Pediatrics. Retrieved from www.aappublications.org/news

46. van der Laan, L. N., de Ridder, D. T., Viergever, M. A., \& Smeets, P. A. (2011). The first taste is always with the eyes: a meta-analysis on the neural correlates of processing visual food cues. Neurolmage, 55(1), 296-303. https://doi.org/10.1016/j.neuroimage.2010.11.055

47. Toepel, U., Knebel, J.-F., Hudry, J., Le Coutre, J., \& Murray, M. M. (2008). The brain tracks the energetic value in food images. Neurolmage, 44, 967-974. https://doi.org/10.1016/j.neuroimage.2008.10.005

48. Kullmann, S., Pape, A.-A., Heni, M., Ketterer, C., Schick, F., Häring, H.-U., ... Veit, R. (2013). Functional network connectivity underlying food processing: disturbed salience 
and visual processing in overweight and obese adults. Cerebral Cortex (New York, N.Y. : 1991), 23(5), 1247-1256. https://doi.org/10.1093/cercor/bhs124

49. Giedd, J. N. (2004). Structural Magnetic Resonance Imaging of the Adolescent Brain. Annals of the New York Academy of Sciences, 1021(1), 77-85. https://doi.org/10.1196/annals.1308.009

50. Mensen, V. T., Wierenga, L. M., van Dijk, S., Rijks, Y., Oranje, B., Mandl, R. C. W., \& Durston, S. (2017). Development of cortical thickness and surface area in autism spectrum disorder. Neurolmage. Clinical, 13, 215-222. https://doi.org/10.1016/j.nicl.2016.12.003

51. Liang, J., Matheson, B. E., Kaye, W. H., \& Boutelle, K. N. (2014). Neurocognitive correlates of obesity and obesity-related behaviors in children and adolescents. International Journal of Obesity, 38(4), 494-506. https://doi.org/10.1038/ijo.2013.142

52. Reinert, K. R. S., Po'e, E. K., \& Barkin, S. L. (2013). The Relationship between Executive Function and Obesity in Children and Adolescents: A Systematic Literature Review. Journal of Obesity, 2013(2), 1-10. https://doi.org/10.1155/2013/820956

53. Essen, D. C. Van. (1997). A tension-based theory of morphogenesis and compact wiring in the central nervous system. Nature, 385(6614), 313-318. https://doi.org/10.1038/385313a0

54. Wilhelm, I., Nyul-Toth, A., Suciu, M., Hermenean, A., \& Krizbai, I. (2016). Heterogeneity of the blood-brain barrier. https://doi.org/10.1080/21688370.2016.1143544

55. Phares, T. W., Kean, R. B., Mikheeva, T., \& Hooper, D. C. (2006). Regional Differences in Blood-Brain Barrier Permeability Changes and Inflammation in the Apathogenic Clearance of Virus from the Central Nervous System. https://doi.org/10.4049/jimmunol.176.12.7666

56. Hutton, C., Draganski, B., Ashburner, J., \& Weiskopf, N. (2009). A comparison between voxel-based cortical thickness and voxel-based morphometry in normal aging. Neurolmage, 48(2), 371-380. https://doi.org/10.1016/j.neuroimage.2009.06.043; 10.1016/j.neuroimage.2009.06.043

57. Adams, R. A., Bauer, J., Flick, M. J., Sikorski, S. L., Nuriel, T., Lassmann, H., ... Akassoglou, K. (2007). The fibrin-derived gamma377-395 peptide inhibits microglia activation and suppresses relapsing paralysis in central nervous system autoimmune disease. The Journal of Experimental Medicine, 204(3), 571-582. https://doi.org/10.1084/jem.20061931

58. Cortes-Canteli, M., Mattei, L., Richards, A. T., Norris, E. H., \& Strickland, S. (2015). Fibrin deposited in the Alzheimer's disease brain promotes neuronal degeneration. Neurobiology of Aging, 36(2), 608-617. https://doi.org/10.1016/j.neurobiolaging.2014.10.030

59. Jenkins, D. R., Craner, M. J., Esiri, M. M., \& DeLuca, G. C. (2018). Contribution of Fibrinogen to Inflammation and Neuronal Density in Human Traumatic Brain Injury. Journal of Neurotrauma, 35(19), 2259-2271. https://doi.org/10.1089/neu.2017.5291

60. Cazettes, F., Cohen, J. I., Yau, P. L., Talbot, H., \& Convit, A. (2011). Obesity-mediated inflammation may damage the brain circuit that regulates food intake. Brain Research, 1373, 101-109. https://doi.org/10.1016/j.brainres.2010.12.008 


\section{SUPPLEMENTARY MATERIAL}

Appendix A.1 - Flow of included and excluded participants in the study.

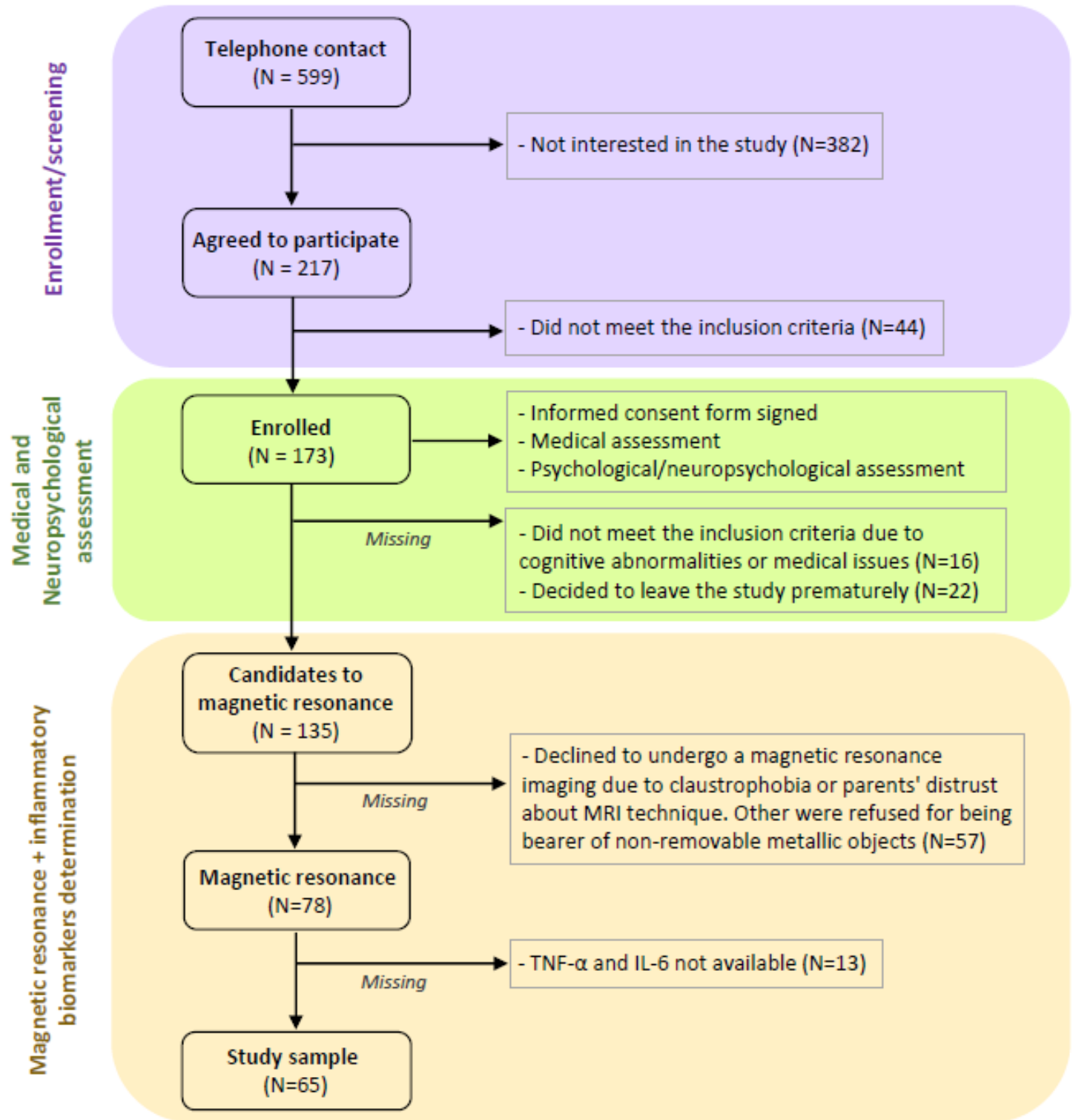


Appendix A.2 - Examined standardized residuals in regression models of inflammation biomarkers.

\begin{tabular}{|c|c|c|c|c|c|}
\hline CODE & $\begin{array}{c}\text { Standardized } \\
\text { Residual }\end{array}$ & $\begin{array}{c}\text { Cook's } \\
\text { Distance }\end{array}$ & $\begin{array}{c}\text { Centered } \\
\text { Leverage Value }\end{array}$ & $\begin{array}{l}\text { Mahalanobis } \\
\text { Distance }\end{array}$ & $\begin{array}{l}\text { Covariance } \\
\text { Ratio (CVR) }\end{array}$ \\
\hline \multicolumn{6}{|l|}{ L-LOC } \\
\hline OI064 & -2.21561 & .05003 & .00421 & .26928 & .89240 \\
\hline OI017 & -2.17765 & .03896 & .00053 & .03382 & .89485 \\
\hline $\mathrm{Cl} 055$ & 2.08438 & .06948 & .01470 & .94106 & .91855 \\
\hline $\mathrm{Cl065}$ & 2.05370 & .03808 & .00205 & .13110 & .91252 \\
\hline \multicolumn{6}{|c|}{ L-Fusiform thickness } \\
\hline OI045 & -2.07634 & .04274 & .00369 & .23635 & .91086 \\
\hline SI032 & 2.03314 & .03901 & .00281 & .17987 & .91579 \\
\hline \multicolumn{6}{|c|}{ R-Superior frontal area } \\
\hline $\mathrm{Cl} 068$ & -2.00486 & .03502 & .00146 & .09347 & .91833 \\
\hline OI067 & 3.20944 & .10903 & .00493 & .31579 & .73150 \\
\hline Ol049 & 2.88932 & .07617 & .00223 & .14255 & .78661 \\
\hline
\end{tabular}

$L=$ left; $R=$ right; $L O C=$ lateral occipital cortex. 
Appendix A.3 - Spearman correlations between BMIz and inflammatory biomarkers with adjusted $p$-value.

\begin{tabular}{|c|c|c|}
\hline \multicolumn{3}{|c|}{ Rho de Spearman } \\
\hline & & BMIz \\
\hline hs-CRP & $\begin{array}{l}\text { Correlation coefficient } \\
\text { Sig (bilateral) }\end{array}$ & $\begin{array}{c}0.568 \\
<0.001^{* * *}\end{array}$ \\
\hline IL-6 & $\begin{array}{l}\text { Correlation coefficient } \\
\text { Sig (bilateral) }\end{array}$ & $\begin{array}{c}0.559 \\
<0.001^{* * *}\end{array}$ \\
\hline TNF- $\alpha$ & $\begin{array}{l}\text { Correlation coefficient } \\
\text { Sig (bilateral) }\end{array}$ & $\begin{array}{c}0.320 \\
0.009 * *\end{array}$ \\
\hline Fibrinogen & $\begin{array}{l}\text { Correlation coefficient } \\
\text { Sig (bilateral) }\end{array}$ & $\begin{array}{c}0.514 \\
<0.001 * * *\end{array}$ \\
\hline \multicolumn{3}{|c|}{ Bonferroni adjusted $p$-value } \\
\hline & & BMIz \\
\hline hs-CRP & $\begin{array}{l}\text { Correlation coefficient } \\
\text { Sig (bilateral) }\end{array}$ & $\begin{array}{c}0.568 \\
<0.001 * * *\end{array}$ \\
\hline IL-6 & $\begin{array}{l}\text { Correlation coefficient } \\
\text { Sig (bilateral) }\end{array}$ & $\begin{array}{c}0.559 \\
<0.001 * * *\end{array}$ \\
\hline TNF- $\alpha$ & $\begin{array}{l}\text { Correlation coefficient } \\
\text { Sig (bilateral) }\end{array}$ & $\begin{array}{c}0.320 \\
0.036^{*}\end{array}$ \\
\hline Fibrinogen & $\begin{array}{l}\text { Correlation coefficient } \\
\text { Sig (bilateral) }\end{array}$ & $\begin{array}{c}0.514 \\
<0.001^{* * *}\end{array}$ \\
\hline
\end{tabular}

hs-CRP = high-sensitivity C-reactive protein; IL-6 = Interleukin-6; TNF- $\alpha=$ tumor necrosis factor alpha; ${ }^{*} p<0.05 ;{ }^{* *} p<0.01 ; * * \mathrm{p}<0.001$. 
Appendix A.4 - Backward multiple linear regression models exploring the influence of all inflammatory parameters with each significant cluster linked to an increase in BMI.

Table A.4.1

Backward regression models examining the link between the left LOC thickness and inflammation biomarkers.

\begin{tabular}{|c|c|c|c|c|c|c|c|}
\hline \multicolumn{2}{|c|}{ Model } & \multirow{2}{*}{$\frac{\beta}{0.19}$} & \multirow{2}{*}{$\frac{t}{1.23}$} & \multirow{2}{*}{$\frac{S E}{0.02}$} & \multirow{2}{*}{$\frac{p}{0.222}$} & \multirow[t]{2}{*}{${ }^{+} R^{2}$} & \multirow{2}{*}{$\begin{array}{l}\text { Sig. F } \\
\text { Change }\end{array}$} \\
\hline 1 & hs-CRP & & & & & & \\
\hline & IL-6 & -0.06 & -0.40 & 0.04 & 0.693 & \multirow{3}{*}{0.18} & \multirow{3}{*}{0.003} \\
\hline & TNF- $\alpha$ & -0.12 & -1.00 & 0.33 & 0.323 & & \\
\hline & Fibrinogen & -0.50 & -3.41 & 0.18 & $0.001^{* *}$ & & \\
\hline \multirow[t]{3}{*}{2} & hs-CRP & 0.16 & 1.18 & 0.02 & 0.242 & \multirow{3}{*}{0.19} & \multirow{3}{*}{0.693} \\
\hline & TNF- $\alpha$ & -0.12 & -1.00 & 0.32 & 0.319 & & \\
\hline & Fibrinogen & -0.52 & -3.62 & 0.17 & $0.001 * *$ & & \\
\hline \multirow[t]{2}{*}{3} & hs-CRP & 0.16 & 1.18 & 0.02 & 0.241 & \multirow{2}{*}{0.19} & \multirow{2}{*}{0.319} \\
\hline & Fibrinogen & -0.55 & -3.93 & 0.17 & $<0.001 * * *$ & & \\
\hline 4 & Fibrinogen & -0.45 & -3.99 & 0.14 & $<0.001 * * *$ & 0.19 & 0.241 \\
\hline
\end{tabular}

$L O C=$ lateral occipital cortex; $S E=$ standard error; ${ }^{+}$Adjusted $R$ squared value; $h s-C R P=$ highsensitivity C-reactive protein; IL-6 = Interleukin-6; TNF- $\alpha=$ tumor necrosis factor alpha; ${ }^{* *} p<$ $0.01 ; * * p<0.001$.

Table A.4.2

Backward regression models examining the link between the left fusiform thickness and inflammation biomarkers.

\begin{tabular}{|c|c|c|c|c|c|c|c|}
\hline \multicolumn{2}{|c|}{ Model } & \multirow{2}{*}{$\frac{\beta}{-0.10}$} & \multirow{2}{*}{$\frac{t}{-0.59}$} & \multirow{2}{*}{$\frac{S E}{0.02}$} & \multirow{2}{*}{$\frac{p}{0.559}$} & \multirow[t]{2}{*}{${ }^{+} R^{2}$} & \multirow{2}{*}{$\begin{array}{l}\text { Sig. F } \\
\text { Change }\end{array}$} \\
\hline 1 & hs-CRP & & & & & & \\
\hline & IL-6 & 0.06 & 0.42 & 0.05 & 0.675 & \multirow{3}{*}{0.06} & \multirow{3}{*}{0.115} \\
\hline & TNF- $\alpha$ & -0.02 & -0.18 & 0.35 & 0.855 & & \\
\hline & Fibrinogen & -0.30 & -1.89 & 0.19 & 0.064 & & \\
\hline \multirow[t]{3}{*}{2} & hs-CRP & -0.10 & -0.59 & 0.02 & 0.556 & \multirow{3}{*}{0.07} & \multirow{3}{*}{0.855} \\
\hline & IL-6 & 0.06 & 0.43 & 0.05 & 0.673 & & \\
\hline & Fibrinogen & -0.30 & -1.98 & 0.19 & 0.052 & & \\
\hline \multirow[t]{2}{*}{3} & hs-CRP & -0.07 & -0.47 & 0.02 & 0.644 & \multirow{2}{*}{0.08} & \multirow{2}{*}{0.673} \\
\hline & Fibrinogen & -0.29 & -1.95 & 0.18 & 0.056 & & \\
\hline 4 & Fibrinogen & -0.33 & -2.77 & 0.14 & $0.007 * *$ & 0.09 & 0.644 \\
\hline
\end{tabular}


Table A.4.3

Backward regression models examining the link between the right precentral thickness and inflammation biomarkers.

\begin{tabular}{|c|c|c|c|c|c|c|c|}
\hline \multicolumn{2}{|c|}{ Model } & \multirow{2}{*}{$\frac{\beta}{0.09}$} & \multirow{2}{*}{$\frac{t}{0.53}$} & \multirow{2}{*}{$\frac{S E}{0.02}$} & \multirow{2}{*}{$\frac{P}{0.600}$} & \multirow[t]{2}{*}{${ }^{+} R^{2}$} & \multirow[t]{2}{*}{$\begin{array}{l}\text { Sig. F } \\
\text { Change }\end{array}$} \\
\hline 1 & hs-CRP & & & & & & \\
\hline & IL-6 & -0.05 & -0.33 & 0.05 & 0.740 & \multirow{3}{*}{-0.002} & \multirow{3}{*}{0.428} \\
\hline & TNF- $\alpha$ & 0.01 & 0.08 & 0.36 & 0.935 & & \\
\hline & Fibrinogen & -0.27 & -1.64 & 0.20 & 0.106 & & \\
\hline \multirow[t]{3}{*}{2} & hs-CRP & 0.09 & 0.53 & 0.02 & 0.597 & \multirow{3}{*}{0.02} & \multirow{3}{*}{0.935} \\
\hline & IL-6 & -0.05 & -0.34 & 0.05 & 0.738 & & \\
\hline & Fibrinogen & -0.26 & -1.67 & 0.19 & 0.100 & & \\
\hline \multirow[t]{2}{*}{3} & hs-CRP & 0.07 & 0.44 & 0.02 & 0.664 & \multirow{2}{*}{0.03} & \multirow{2}{*}{0.738} \\
\hline & Fibrinogen & -0.28 & -1.82 & 0.19 & $0.074^{\mathrm{a}}$ & & \\
\hline 4 & Fibrinogen & -0.24 & -1.94 & 0.15 & $0.057^{a}$ & 0.04 & 0.664 \\
\hline
\end{tabular}

Table A.4.4

Linear regression models examining the association between the left rostral middle frontal surface area and inflammation biomarkers.

\begin{tabular}{|c|c|c|c|c|c|c|c|}
\hline \multicolumn{2}{|c|}{ Model } & \multirow{2}{*}{$\frac{\beta}{0.27}$} & \multirow{2}{*}{$\frac{t}{1.65}$} & \multirow{2}{*}{$\frac{S E}{0.02}$} & \multirow{2}{*}{$\frac{p}{0.104}$} & \multirow[t]{2}{*}{${ }^{+} R^{2}$} & \multirow[t]{2}{*}{$\begin{array}{c}\text { Sig. F } \\
\text { Change } \\
\end{array}$} \\
\hline 1 & hs-CRP & & & & & & \\
\hline & IL-6 & -0.13 & -0.87 & 0.05 & 0.387 & \multirow{3}{*}{0.04} & \multirow{3}{*}{0.175} \\
\hline & TNF- $\alpha$ & 0.04 & 0.28 & 0.35 & 0.780 & & \\
\hline & Fibrinogen & 0.13 & 0.83 & 0.19 & 0.412 & & \\
\hline \multirow[t]{3}{*}{2} & hs-CRP & 0.27 & 1.66 & 0.02 & 0.102 & \multirow{3}{*}{0.05} & \multirow{3}{*}{0.780} \\
\hline & IL-6 & -0.13 & -0.88 & 0.05 & 0.383 & & \\
\hline & Fibrinogen & 0.14 & 0.91 & 0.19 & 0.365 & & \\
\hline \multirow[t]{2}{*}{3} & hs-CRP & 0.22 & 1.44 & 0.02 & 0.156 & \multirow{2}{*}{0.06} & \multirow{2}{*}{0.383} \\
\hline & Fibrinogen & 0.12 & 0.73 & 0.18 & 0.469 & & \\
\hline 4 & hs-CRP & 0.28 & 2.31 & 0.01 & $0.024^{*}$ & 0.06 & 0.469 \\
\hline
\end{tabular}


Table A.4.5

Linear regression models examining the link between the right superior frontal surface area and inflammation biomarkers.

\begin{tabular}{|c|c|c|c|c|c|c|c|}
\hline \multicolumn{2}{|c|}{ Model } & \multirow{2}{*}{$\frac{\beta}{0.09}$} & \multirow{2}{*}{$\frac{t}{0.54}$} & \multirow{2}{*}{$\frac{S E}{0.02}$} & \multirow{2}{*}{$\frac{p}{0.593}$} & \multirow[t]{2}{*}{${ }^{+} R^{2}$} & \multirow[t]{2}{*}{$\begin{array}{c}\text { Sig. F } \\
\text { Change }\end{array}$} \\
\hline 1 & hs-CRP & & & & & & \\
\hline & IL-6 & -0.003 & -0.02 & 0.05 & 0.984 & \multirow{3}{*}{0.06} & \multirow{3}{*}{0.107} \\
\hline & TNF- $\alpha$ & 0.30 & 2.36 & 0.35 & $0.021^{*}$ & & \\
\hline & Fibrinogen & 0.05 & 0.30 & 0.19 & 0.765 & & \\
\hline \multirow[t]{3}{*}{2} & hs-CRP & 0.09 & 0.58 & 0.02 & 0.564 & \multirow{3}{*}{0.07} & \multirow{3}{*}{0.984} \\
\hline & TNF- $\alpha$ & 0.30 & 2.38 & 0.34 & $0.020 *$ & & \\
\hline & Fibrinogen & 0.05 & 0.31 & 0.18 & 0.761 & & \\
\hline \multirow[t]{2}{*}{3} & hs-CRP & 0.11 & 0.93 & 0.01 & 0.356 & \multirow{2}{*}{0.09} & \multirow{2}{*}{0.761} \\
\hline & TNF- $\alpha$ & 0.31 & 2.52 & 0.33 & $0.014^{*}$ & & \\
\hline 4 & TNF- $\alpha$ & 0.32 & 2.70 & 0.33 & $0.009 * *$ & 0.09 & 0.356 \\
\hline
\end{tabular}

